\title{
Targeting TRPM8 for Pain Relief
}

\author{
Carlos Fernández-Peña and Felix Viana*
}

Instituto de Neurociencias de Alicante, Universidad Miguel Hernández-CSIC, 03550, San Juan de Alicante, Spain

\begin{abstract}
Transient receptor potential melastatin 8 (TRPM8) is a non-selective cation channel activated by cold temperature and cooling agents. TRPM8 is expressed in peripheral cold thermoreceptors and plays a fundamental role in sensing mild, cool temperatures. In addition, cumulative evidence obtained in humans and different animals models, combined with pharmacological and gene silencing techniques, suggest that TRPM8 may also play a role in cold discomfort and the pathophysiology of cold pain. This article reviews the available evidence in a critical fashion. In addition, the article reviews the possible role of TRPM8 in basal tearing, cold urticaria and airway irritation. Collectively, these results suggest that pharmacological modulators of TRPM8 could have potential indications in a variety of conditions, including dry eye disease, airway irritation, teeth hypersensitivity, migraine and neuropathic pain. However, additional studies, especially in humans, are needed to verify these preliminary observations. The paucity of potent, specific pharmacological TRPM8 antagonists available is a current limitation for further progress in this field.
\end{abstract}

Keywords: Cold, thermoreceptor, menthol, icilin, somatosensory transduction, TRPA1, TRP channel.

\section{INTRODUCTION}

Hypersensitivity to cold temperature, manifested clinically as cold hyperalgesia or cold allodynia, is a frequent, disabling, symptom in patients suffering with neuropathic pain [1-4]. Allodynia is a term that describes pain due to a stimulus (cold temperature in this particular case) that does not normally provoke pain. Cold allodynia is also evident in animal models of peripheral nerve injury [5]. In some cases, including traumatic upper extremity nerve injuries [6] and the neuropathy associated with oxaliplatin treatment [7], cold hyperalgesia and cold allodynia are the most prevalent symptoms reported by patients. Like other neuropathic symptoms, cold pain is difficult to manage, with poor treatment outcomes. Despite rapid advances in this field [8], it is still unclear the precise role of specific transducer molecules in the mechanisms of cold pain [9].

In the past decade, the role of Transient Receptor Potential (TRP) ion channels in cold temperature sensing has been firmly established [reviewed by 10,11]. In particular, TRPM8 and TRPA1 have been identified in two distinct populations of peripheral sensory neurons and are thought to play differential roles in cold sensing. The canonical view gives TRPM8 a critical role in innocuous, mild, cold temperature sensing [12-14]. In contrast, the threshold of activation, the expression within peptidergic nociceptors and behavioural results suggest that TRPA1 is a noxious cold sensor $[15,16]$. It should be noted from the start that this dichotomy is an oversimplification: the transduction and encoding of cold stimuli is a complex phenomenon that

*Address correspondence to this autor at the Instituto de Neurociencias de Alicante, Universidad Miguel Hernández-CSIC, Apartado 18, San Juan de Alicante, 03550 Spain; Tel: 34-96-591-9347; Fax: 34-96-591-9561;

E-mail: felix.viana@umh.es involves the operation of more than just these two ion channels $[9,17]$.

Transient receptor potential melastatin 8 (TRPM8) is a cold-activated cation channel expressed in a small subpopulation of peripheral sensory neurons $[18,19]$. TRPM8 is also activated by menthol, the natural cooling agent present in peppermint leaves, and by other natural and synthetic cooling compounds [20]. Activation of TRPM8 plays an important role in thermosensation [21] and thermosensation is a major component of the pain sensation. Therefore, it is anticipated that thermosensitive channels, including TRPM8, should be relevant players in pain.

The structure, expression, functional characteristics and pharmacology of TRPM8 channels have been extensively reviewed in recent publications $[9,20,22-26]$. In this short review article, we will try to avoid excessive overlap with previous reviews, focusing instead on those aspects of TRPM8 function that are less well understood. We try to address a very specific question: is TRPM8 a molecular target with therapeutic potential in the pain field? If so, should we focus our efforts on developing specific TRPM8 agonists or antagonists? In other words, is TRPM8 activation analgesic or proalgesic? Answering this basic question may not be as simple as anticipated. For example, in the case of TRPV1, both, agonists and antagonists have shown therapeutic potential in the treatment of pain [27, 28].

\section{SOME BASIC FACTS ABOUT TRPM8 CHANNELS}

In humans, the TRPM8 protein is 1104 amino acids long, with 6 transmembrane (TM) domains, a pore P-loop between the fifth and sixth TM domains and both ends located intracellularly. TRPM8 is thought to assemble into a tetramer, forming a non-selective cation channel with a modest permeability to calcium. In recombinant expression 
systems, TRPM8 is stimulated by temperatures below 25$28^{\circ} \mathrm{C}$ [18]. In contrast, activation of transient receptor potential ankyrin 1 (TRPA1), another cold-activated TRP channel, requires lower temperatures, with a threshold below $18^{\circ} \mathrm{C}$ [15]. These absolute threshold values are probably not very meaningful in vivo because many TRPM8-expressing cold-sensitive neurons respond to minute temperature drops below $34^{\circ} \mathrm{C}$ [29-31]. As a matter of fact, mammalian cold thermoreceptors are characterized by spontaneous firing at normal skin temperatures, and this activity is strongly temperature sensitive [reviewed by 32]. Both cooling and menthol shift the voltage activation curve of TRPM8 towards more negative potentials. This effect leads to an increase in the probability of channel opening and larger inward currents at physiological membrane potentials [23, 31, 33]. Many antagonist have an opposite effect on voltagedependent gating of TRPM8 [34, 35]. A number of factors modulate the sensitivity of TRPM8 channels to temperature [reviewed by 22], including membrane PIP $_{2}$ levels $[36,37]$, PKC-dependent dephosphorylation [38, 39], phospholipase A2 activity [40], proinflammatory mediators [41] and polyphosphates [42]. The activity of TRPM8 is also modulated by its specific localization within membrane lipids rafts $[43,44]$ and by posttranslational modifications, such as glycosylation [45-47]. Very little is known about endogenous modulators of TRPM8 activity [48].

Recently, Bidaux et al. reported on splice variants of TRPM8 in prostate tissue [49]. These short isoforms add complexity to the regulation of TRPM8 because they act as dominant negative subunits, antagonizing channel opening by cold temperature. The authors did not detect the short isoforms of TRPM8 in human dorsal root ganglia (DRG).

\section{CHEMICAL AND FUNCTIONAL CHARACTERIS- TICS OF TRPM8-EXPRESSING NEURONS}

Good progress has been made in characterizing the molecular and functional phenotype of TRPM8-expressing neurons, specially since the generation of transgenic mouse lines that label this subpopulation of sensory neurons [5052].

TRPM8 resides primarily in small diameter, nonpeptidergic (but see below), non-IB4, expressing, neurons within the dorsal root and trigeminal ganglia $[18,19,50,51$, 53]. Neurochemical markers suggest that TRPM8 is expressed in unmyelinated $\mathrm{C}$-fibers and lightly myelinated A $\delta$ fibers [50]. Peripheral terminals of sensory neurons innervating the skin, tongue, teeth, colon, cornea also express TRPM8 [50-54]. More recent studies indicate that a small fraction of TRPM8-expressing fibers co-express neuropetides (e.g. CGRP), both, in rodents [50] and humans [55], suggesting that these fibers may represent a functionally non-uniform population. Sensory neurons expressing TRPM8 project to superficial laminae of the spinal cord dorsal horn, in particular to lamina I and the outer region of lamina II, similar to the termination of CGRP-containing fibers [50]. In cold receptor fibers, menthol, at micromolar concentrations, causes a marked increase in the mean firing frequency and a shift to warmer values of the stimulus response curve $[52,56,57]$.

The co-expression of TRPV1 in a fraction of TRPM8containing neurons, suggested by dual responses to menthol and capsaicin [18, 58-60], has been controversial and ascribed to culturing artefacts [15], but has been confirmed in subsequent studies in intact fibers [50, 52, 54]. An important study by Xing and colleagues showed that TRPM8 channels were expressed on two distinct classes of coldsensitive DRG neurons. One class had non-nociceptive characteristics, including lack of responses to capsaicin and ATP. In contrast, the other class was activated by algesic substances (ATP, capsaicin and low $\mathrm{pH}$ ) [61]. This was an early indication that TRPM8 may play a role in sensing cold pain. Furthermore, the nerve endings of TRPM8-containing fibers terminate in peripheral zones mediating distinct perceptions of cold and pain, suggesting that TRPM8 expressing neurons may be responsible for a wide range of sensory functions [50]. Another experimental strategy documenting the degree of overlap between TRPM8 and TRPV1 comes from studies using the ultrapotent vanilloid agonist resiniferatoxin. In rats treated systemically with resiniferatoxin, mRNA levels for TRPV1 and TRPA1 decreased by more than $50 \%$. In contrast, TRPM8 levels decreased only $8 \%$, a non-significant effect [62]. Similar results were obtained in a different study [63]. This result suggests a low level of co-expression of TRPM8 and nociceptor markers.

The biophysical and pharmacological properties of the non-selective cation currents activated by cold (Icold) found in cold-sensitive neurons are consistent with the properties of TRPM8-dependent currents measured in transfected cells $[31,64,65]$. The temperature threshold of cultured coldsensitive neurons is modulated by TRPM8 expression levels (here expression is meant in a functional sense) and by the co-expresison of voltage-gated, dendrotoxin-sensitive, Kv1 potassium channels [66]. Interestingly, local injection of dendrotoxin and 4-AP increased the nocifensive responses to cold in mice, suggesting that changes in the excitability of cold afferents could trigger cold pain [9].

About $20 \%$ of neurons in the DRG are activated by noxious cold stimulation, producing differential biochemical changes in TRPM8 and TRPA1-expressing neurons [67]. About $50 \%$ of TRPM8-expressing neurons showed rapid activation of extracellular signal-regulated protein kinase (ERK) following a cold stimulus of $4^{\circ} \mathrm{C}$. In contrast, most TRPA1-activated neurons showed strong phosphorylation of p38. Both kinases are activated by intracellular calcium elevation but it is unclear what the functional consequences of these changes are on cold-sensing neurons. In contrast, mild cooling, sufficient to activate cold thermoreceptors, did not result in the phosphorylation of ERK [68].

\section{THE EXPRESSION AND FUNCTION OF TRPM8 FOLLOWING NERVE INJURY}

A number of studies have investigated changes in the expression of several TRP channels, including TRPA1 and TRPM8, in different experimental models of chronic pain. These models are accompanied by lasting alterations in cold sensitivity, such as cold allodynia and cold hyperalgesia. The results reported are quite variable, with considerable inconsistencies in the findings.

Mice with a sciatic nerve injury responded in the acetone test with enhanced nocifensive behaviors, and these 
responses were abolished in TRPM8 knock out mice [14]. In the spinal nerve ligation (SNL) model of neuropathic pain [5] in rats, TRPM8 levels, measured by in-situ hybridization decreased in injured DRG (L5) and remained unchanged in the neighbouring, uninjured, L4 DRG [69]. Moreover, in the same model TRPA1 levels increased at L4 and decreased at L5 [69, 70]. In this model of nerve injury, the same authors showed that antisense knock down of TRPA1 by intrathecal delivery, but not TRPM8, alleviated cold hyperalgesia [71]. In different mice strains subject to a SNL lesion both, TRPM8 and TRPA1 levels decreased markedly in the injured DRGs [72]. In the (SNL) model in rats, the percentage of uninjured mechanosensitive $\mathrm{C}$ fibers responding to strong cold (i.e $0^{\circ} \mathrm{C}$ ) or icilin, examined in an in vitro skin-nerve preparation, did not change significantly [73]. In contrast, the percentage of mechanosensitive $A \delta$ fibers responding to cold stimulation or icilin nearly doubled in the SNL group. Because Ruthenium Red, a blocker of TRPA1 without effects on TRPM8, reduced icilin-induced activity significantly, the authors concluded that the effects were likely mediated by TRPA1. In culture, similar increments in the percentage of cold-sensitive neurons among uninjured afferents have been observed [73, 74]. The increase in the percentage of mustard oil-sensitive neurons, suggested the involvement of TRPA1 channels [70].

In the chronic constriction injury (CCI) model in rats, TRPM8 RNA levels showed a delayed increase (statistically significant increase at 14 days post-CCI, but not 7 days postCCI surgery) in affected DRG neurons [62]. In the same model, immunostaining revealed an increase in the percentage of TRPM8-immunoreactive neurons when compared with the sham-operated group [75]. Systemic application of capsazepine, a non-specific blocker of TRPM8 channels reduced the cold-evoked symptoms [75]. These findings could not be reproduced in mice with CCI, and the very opposite was found: they showed a decrease in TRPM8 and TRPA1 mRNA levels, despite persistent cold and menthol hypersensitivity [76]. The levels of TREK-1 decreased as well. The percentage of TRPM8 and TRPA1expressing neurons in the DRG, measured by in-situ hybridization, were also reduced significantly 7-14 days following the injury. Moreover, in calcium imaging experiments, the authors found no alterations in the number of cold or menthol responsive neurons in the DRG [76].

In summary, we can conclude that the correlation between behavioural responses to cold following nerve injury and the expression of TRPM8 or TRPA1 is generally very poor. Moreover, a phenotypic switch in the expression of TRPM8 or TRPA1 among injured neurons is also unlikely. Thus, to explain the persistent cold hypersensitivity following injury we should look for alternative explanations: modulation in the gating of other channels by cold temperature, expression of other molecular sensors at the peripheral level or a systems level explanation that involves alterations in the processing of nociceptive information at central levels. Regardless, an important caveat in most of these studies is the fact that mRNA abundance (often just one mRNA species was examined) may not accurately reflect protein levels and/or ion channel function [77].

\section{THE ANALGESIC EFFECT OF TRPM8 ACTIVA- TION}

Moderate cooling, the physiological stimulus of TRPM8expressing peripheral thermoreceptors, has clear analgesic properties in some painful conditions (e.g. osteoarthritis) [78-80]. Cooling the skin can produce a soothing sensation on the background of inflammatory pain. However, these beneficial effects of cold temperature are not necessarily TRPM8-mediated [81]. For example, the reduction in firing rate of capsaicin-sensitized nociceptors produced by cooling [82] are likely due to an antagonist effect of cold temperature on TRPV1 channels [33, 83]. In contrast, ischemic block of cold-specific afferent input can unmask cold-induced burning pain $[84,85]$, suggestive of central interactions between different thermosensitive inputs.

Natural agonists of TRPM8 such as menthol, a cyclic terpene alcohol extracted from peppermint leaves (mentha piperita), have been used for centuries due to their analgesic, antipruritic and counterirritant effects [86-88]. Menthol is used in over the counter medications to treat cold symptoms and pain in toothpastes, beverages, and also in cigarettes. Menthol can be applied topically on the skin, as a mouthwash, or inhaled to reduce cough or irritation of the airways. Human psychophysical studies indicate that the actions of menthol on sensory perception are rather complex. In one study, the author found that application of menthol to the human skin raised the threshold for the sensation of a warm stimulus, without changing the threshold for heat pain [89]. In another study, the same author found that menthol can transiently reduce the sensory irritation produced by capsaicin [90]. Both, cooling the skin and menthol (1\%), can relieve the sensation of itch produced by intradermal histamine injection [91], a finding at odds with a previous study [92].

Similar to reports in humans, behavioural responses to topical menthol in rodents are also complex. A recent study found that low $(0.01$ to $1 \%)$ and high $(10-40 \%)$ concentrations of menthol had opposite effects on thermal preference in rats, with decreased cold avoidance at high concentrations [93]. Proudfoot and colleagues showed that TRPM8 agonists, including menthol, relieved pain in certain neuropathic models [94]. The main difference with the opposite effects described by Caspani et al. (see below) is the much higher concentration of menthol used in the later study [76]. It is important to emphasize that these effects of menthol are not necessarily TRPM8-dependent since menthol is also known to inhibit voltage-gated sodium [95, 96] and calcium channels [97], which could reduce nociceptive transmission. Menthol has additional pharmacological effects, including activation of ionotropic $\mathrm{GABA}_{\mathrm{A}}$ receptors $[98,99]$. For example, the depressant action of menthol on respiratory rhythm generation in the brainstem has been ascribed to a $\mathrm{GABA}_{\mathrm{A}}$-mediated effect [100].

In a recent study, expression of TRPM8 was found in a subpopulation of nociceptive afferents innervating the colonic wall. Interestingly, activation of individual fibers by icilin resulted in a marked desensitization to capsaicin and also to mechanosensitive responses mediated by TRPA1 [54]. These results suggest that activation of TRPM8 could have an antinociceptive effect in visceral afferents. Indeed, 
several studies have reported on the beneficial effects of peppermint oil in the treatment of irritable bowel syndrome [reviewed by 101].

\section{THE ALGESIC EFFECT OF TRPM8 ACTIVATION}

In healthy volunteers, a decrease in skin temperature from $34^{\circ} \mathrm{C}$ towards $0^{\circ} \mathrm{C}$ evokes a monotonic increase in cold pain. However, it is worth noting that reported cold pain thresholds vary widely across individuals and across studies: $10^{\circ} \mathrm{C}$ to $14^{\circ} \mathrm{C}[102], 0^{\circ} \mathrm{C}$ to $25.5^{\circ} \mathrm{C}$ [103]. Another study reported $18 \%$ of non-responders for a stimulus of $5^{\circ} \mathrm{C}$, usually considered a severe noxious cold stimulus [104] Although TRPM8 would be strongly activated at these low temperatures, they can not be considered a specific stimulus for TRPM8-containing nerve terminals because other nerve afferents are also activated in this temperature range, as evidenced by recordings in TRPM8 KO mice $[12,105]$. Notably, very mild cold temperatures $\left(25-30^{\circ} \mathrm{C}\right)$ can also evoke cold pain, a sensation termed innocuous cold nociception [106].

Several studies, both in animal models and in humans, have concluded that activation of TRPM8 can produce pain or discomfort. One potential problem with some of these studies is the fact that involvement of TRPM8 was deduced solely on the actions of menthol, assuming a specific activation of menthol on TRPM8 when applied to the skin. If this was the case, one would predict the absence of responses to menthol in sensory neurons of TRPM8-deficient mice. This expectation was only fulfilled in the study by Bautista et al:: menthol responses were abolished in DRG neurons of TRPM8 KO mice, compared to $16.9 \%$ responses in wiltype animals [12]. In contrast, in the study by Colburn and colleagues, responses to menthol were markedly reduced but not abolished, changing from $21 \%$ in wiltype to $4.9 \%$ of the neurons in TRPM8 KO mice [14]. Of note, in a third transgenic line of TRPM8-deficient animals, responses to menthol were only $1.4 \%$, compared to $4.2 \%$ in wildtype DRG neurons [13], a similar ratio to the study by Colburn despite the much lower level of responses. The clear differences between these studies are rather puzzling although we should not forget that in all three cases, neurons were maintained in culture. Regardless, menthol also activates TRPA1, a nociceptor-specific channel expressed in sensory terminals as well [107, 108], and TRPV3, a warmactivated TRP channel [109]. A recent study investigated the effect of intradermal application of menthol on cold hypersensitivity in different strains of mice. The results were remarkable: cold hypersensitivity to menthol was abolished in TRPA1 KO mice but developed normally in TRPM8 KO animals [110]. Also interesting, the effect of menthol in TRPM8 KO animals developed on the background of a pronounced basal hyposensitivity to cold.

Sensory responses to topical menthol application to the skin or mouth are complex. Part of the variability may depend on concentration, site and duration of application. At very low concentrations, menthol causes a pleasant cooling sensation in human volunteers [111], consistent with activation of "classical" cold thermoreceptors [112]. At higher concentrations (10-40\%), menthol evokes variable sensations in humans, including coolness, warm, spontaneous pain, cold hyperalgesia [104, 113-115] and shifts in cold pain threshold to warmer temperatures [104,
$114,116,117]$. Interestingly, this shift in cold pain threshold was attenuated by topical application of capsaicin or cinnamaldehyde [116]. Often, pain produced by menthol is described as burning [104, 117]. Microneurographic studies in humans show that menthol also activates cold-sensitive nociceptors [118].

In future studies, it would be useful to test other agonists of TRPM8 channels rather than menthol. Alternatively, one may consider a careful comparison of the effects of different concentrations of menthol $[93,111]$. It is questionable that a $30-40 \%$ solution of any compound (this is the concentration of menthol used most often in human psychophysical studies) could sustain the label of "specific agonist" in any rigorous pharmacological study.

It is also remarkable that $30 \%$ of volunteers reported no cold allodynia or hyperalgesia during menthol application [104]. In a small group of neuropathic pain patients, menthol $(40 \%)$ did not aggravate pre-existing cold allodynia symptoms; in most patients the trend was in the opposite direction (i.e. hypoalgesia) [119]. Perhaps, menthol is having multiple effects (e.g. excitation of TRPM8, inhibition of Nav, etc), or is acting simultaneously on different populations of afferents (e.g. cold-specific thermoreceptors and polymodal nociceptors) interacting at central levels [85]. These multiple effects may balance each other in different ways, leading to variable results.

A recent study by the group of D. McKemy nicely shows that the importance of TRPM8 modulation in pathological cold pain varies in different animal models [35]. The authors used unilateral intraplantar injections of complete Freund's adjuvant (CFA) to mimic inflammatory pain, which results in cold hypersensitivity that is TRPM8-dependent [14]. Intraperiotoneal injection of 1-phenylethyl-4-(benzyloxy)-3methoxybenzyl(2-aminoethyl)carbamate (PBMC), a selective blocker of TRPM8 channels, reduced (but did not abolish) responses to evaporative cooling (i.e. acetone test). They observed similar effects of PBMC, a modest relief, in the CCI model as well. In contrast, PBMC did not alter the time course of cold hypersensitivity produced in the oxaliplatin model.

In the chronic constriction injury (CCI) of neuropathic pain, Su et al. found that TRPM8 expression levels increased with a time course that matched the development of cold allodynia [120], a finding that disagrees with the results of Caspani et al, discussed previously [76]. Moreover, cold allodynia increased after intrathecal application of menthol and decreased after injection of antisense against TRPM8. So far, this is one of the strongest indications of the participation of TRPM8 in cold-induced pain.

In the spinal nerve ligation model, the development of cold hypersensitivity was accompanied by enhanced responses to topical application of $1 \mathrm{mM}$ icilin [73], a TRPM8 and TRPA1 agonist. Of note, the responses to vehicle (1\% DMSO) also increased markedly above baseline in the operated rats.

\section{TRPM8 AND OXALIPLATIN-INDUCED COLD HY- PERALGESIA}

Oxaliplatin is a platinum-based chemotherapeutic agent widely used in the treatment of colorectal cancer. The 
administration of this drug causes multiple neurological side effects, including acute cold-triggered paresthesias and a chronic peripheral neuropathy characterized by mechanical and cold hypersensitivity and minimal alterations in noxious heat sensitivity [121]. The neuropathy is often disabling enough to limit the dosage and the duration of the treatment, and has a negative impact on the quality of life of many patients treated with oxaliplatin [122]. The pathophysiologic mechanisms underlying oxaliplatin-induced toxicity remain unclear.

In animals models of oxaliplatin-induced neuropathy, there have been contrasting reports on the role of TRPM8 and TRPA 1 in the cold hypersensitivity. One study found a transient upregulation of TRPM8 mRNA in mice treated with oxaliplatin [123]. Moreover, the authors showed that i.p. injection of capsazepine, a non-specific inhibitior of TRPM8, reduced cold-evoked responses in treated mice. The pharmacological data obtained by Gauchan and colleagues contrast to those obtained in another recent study. The authors tested PBMC, a novel antagonist of TRPM8 channels, and found no effect on cold hypersensitivity in the oxaliplatin model, despite robust efficacy in other models of cold pain [35]. Nevertheless, allodynic responses in oxaliplatin-treated animals were abolished in TRPM8 KO mice, suggesting a role of these channels in the cold hypersensitivity. In a comprehensive study performed on the same animal model, the elevation in TRPM8 levels could not be replicated [124]. However, in behavioural experiments in which the animals were exposed to cooling ramps from 30 to $0^{\circ} \mathrm{C}$, the oxaliplatin-treated WT mice hardly tolerated temperatures below $15^{\circ} \mathrm{C}$, while TRPM8 ko mice showed virtually no responses to innocuous and noxious cold temperatures. The authors also found that ivabradine, a specific blocker of HCN channels, also blocked the cold hyperalgesia produced by oxaliplatin. Previously, it was shown that TRPM8-expressing cold receptors express high levels of HCN1 channels and pharmacological or genetic reduction of these channels reduced cold-evoked responses in vivo [125]. In light of these findings, Descoueur and colleagues concluded that cold hypersensitivity was due to molecular remodelling of TRPM8-expressing cold nociceptors that became more excitable following oxaliplatin treatment. Altogether, these studies suggest an important role of TRPM8 channels in the cold sensation during the oxaliplatin-induced neuropathy. Balancing these observations are other studies that suggest fundamental roles of TRPA1 [126] and Nav1.6 channels [127] in cold hypersensitivity following oxaliplatin treatment.

\section{TRPM8 AND OROFACIAL/DENTAL PAIN}

Orofacial pain is common in several pathological conditions affecting the sensory branches of the trigeminal nerve. They include many different disorders, such as pain secondary to endodontic procedures, sinusitis, posherpetic neuralgia and trigeminal neuralgia [128, 129]. Typical of many chronic orofacial pain conditions is the presence of cold hypersensitivity [130]. Cold hyperalgesia has also been described in animal models of trigeminal neuropathic pain [131]. TRPM8 channels are expressed in many coldsensitive trigeminal neurons $[18,132]$ and trigeminal nerve endings [50] but their specific involvement in trigeminal cold pain is unknown at present.
Exposure of dentin, resulting from the erosion of the tooth enamel by caries, mechanical and chemical (e.g. acidic beverages) abrasion or gingival retraction can cause a form of localized sharp tooth pain known as tooth hypersensitivity. This hypersensitivity is commonly triggered by cold temperatures within the oral cavity (e.g. a cold drink) but it is still unclear how healthy and injured teeth detect cold temperatures. Proposed mechanisms include fluid movement within dentinal tubules that result in mechanical activation of intradental afferents (hydrodynamic theory), direct activation of trigeminal afferents within the internal dentin layer by cold and sensory responses mediated by odontoblasts [133], the dentin-producing cells at the pulpal-dentinal border [134].

Intradental $\mathrm{A}$ and $\mathrm{C}$ fibers respond to rapid cooling of the dentin surface. Functional analysis of dental primary afferent neurons in rats revealed the expression of three TRP channels involved in thermo sensation: TRPV1, TRPM8 and TRPA1 [135]. Moreover, an important expression of the TTX-resistant Nav1.8, a sodium channel implicated in noxious cold transduction [136], was also found. In this study, some of the TRPM8 positive neurons co-localized with TRPV1, suggesting that nociceptive cold pain could be mediated by TRPM8.

Human odontoblasts express thermosensitive ion channels, including TRPV1, TRPA1 and TRPM8 [137]. Moreover, these cells responded to cold, icilin, cinnamaldehyde and menthol with intracellular calcium elevations [137]. Pharmacological and gene silencing studies suggested the participation of TRPM8 and TRPA1 in these cold-evoked responses. In contrast, mouse and rat odontoblasts express several thermosensitive and mechanosensitive TRP and $\mathrm{K} 2{ }_{\mathrm{P}}$ channels, but lack TRPA1 and TRPM8 [138, 139].

Pulpitis, the inflammation of the tooth pulp, can also trigger neuroplastic changes and sensitization of trigeminal nociceptors, resulting in cold hyperalgesia. In patients diagnosed with irreversible pulpitis, and suffering from cold hyperalgesia, a semiquantitative study showed that the axonal area labelled with TRPM8 pulpal nerves was reduced when compared with normal molar teeth [140]. It should be noted that TRPM8 labelling was missing from the fine axon terminals within the odontoblastic layer, where activation by a cold stimulus seems most likely. In a rat model of tooth injury exposing the pulp, the levels of TRPA1 protein in the trigeminal ganglion increased transiently following injury [141]. This is rather remarkable, considering that neurons innervating the injured teeth must represent a minimal percentage of the total within the trigeminal ganglion.

\section{TRPM8 AND MIGRAINE}

Migraine is a highly prevalent, episodic neurological disorder affecting most commonly women and characterized by severe headaches that are often associated with autonomic symptoms (e.g. nausea) and sensitivity to light and sound. Recently, in a genome wide association study, a TRPM8 gene variant was associated with increased susceptibility to common migraine [142]. Interestingly, TRPM8 was linked to migraine in women only. Although intriguing, it is not clear whether the association between TRPM8 and migraine is causal and what the pathophysiological mechanism is. One 
could speculate that TRPM8 activity is antinociceptive for migrane and is depressed below a critical threshold in migrane sufferers. In this context, it is also worth mentioning that two recent studies provided a clear link between the activity of TRPA1 and two models of headache [143, 144].

\section{TRPM8 AND DRY EYE DISEASE}

The eye surface is innervated by functionally distinct subtypes of trigeminal peripheral nerve endings activated by different physicochemical stimuli. A fraction of these terminals is activated by cold and menthol, suggesting the expression of TRPM8 on their surface [145-147]. Topical application of menthol $(200 \mu \mathrm{M})$ to human eyes produced a transient sensation of 'freshness' often followed by a feeling of warmth. Interestingly, menthol led to the disappearance of thermal sensations of the cornea stimulated with cold air [147].

Dry eye disease is a common ophthalmological problem, particularly in the elderly, characterized by a dryness sensation of the eyes that leads to persistent ocular discomfort and can also decrease visual function [148]. The aetiology and mechanisms involved in dry eye disease are uncertain but ultimately converge on alterations in the tear film that protects the corneal surface $[149,150]$. A recent study found a fundamental role of TRPM8 activation in regulating basal tear secretion in mice [52]. Moreover, tear production in human volunteers was also regulated by corneal surface temperature - basal tearing rate was significantly lower at $43^{\circ} \mathrm{C}$ than at $18-20^{\circ} \mathrm{C}$. This basal tearing is crucial to maintaining ocular surface wetness. Mechanistically, cold-sensitive corneal afferents expressing TRPM8 give rise to the afferent limb of the basal tearing reflex [52]. They detect small temperature variations on the corneal surface, for example, secondary to tear evaporation. Another recent study provided additional pharmacological evidence for the presence of TRPM8 in corneal afferents in rats [151]. These findings open new possibilities for the treatment of dry eye disease with TRPM8 agonists [152]. Other related diseases that are accompanied by dry mucosal surfaces, including burning mouth syndrome and vaginal dryness may also benefit from these observations.

\section{TRPM8 IN THE AIRWAYS}

The upper and lower airways are constantly exposed to changes in temperature during the flow of air in and out of the lung. Airways are densely innervated by sensory terminals that participate in important reflexes (e.g. coughing, sneezing). Some of these afferents are activated by cold temperature and by menthol, suggesting the expression of TRPM8 [153-155].

TRPM8 is also expressed in human bronchial epithelial cells and the activation by cold or menthol increases mucin secretion and inflammatory cytokines by a TRPM8dependent mechanism $[156,157]$. Expression in the bronchial epithelial cells is restricted to a short variant that is localized primarily within the endoplasmic reticulum [157].

Menthol has been used for decades as a flavorant in cigarettes. This practice has generated a strong debate between the tobacco industry, academic researchers and legislators because of the possible influence of menthol on smoking initiation [158]. According to some studies, menthol could facilitate the smoking behaviour by reducing the perceived harshness and/or bitterness of inhaled tobacco smoke. In a recent study, using plethysmography in mice, it was shown that inhaled menthol had potent counterirritant properties on the effects produced by acrolein, acetic acid and cyclohexanone, three airway irritants present in cigarette smoke [159]. The authors concluded that the counterirritant effects of menthol were likely mediated by activation of TRPM8 channels. The authors reached this conclusion based on the effects produced by AMTB, a specific TRPM8 antagonist [160]. However, the effects of AMTB were significant but discrete, with only a mild suppression of the counterirritant effects produced by menthol. To unambiguously demonstrate the contribution of TRPM8 channels to the counterirritant effects of menthol it would have been useful to test the effects on TRPM8-deficient mice. If confirmed, these findings suggest that TRPM8 agonists could be useful in the treatment of chemically-induced airway irritation. As mentioned previously, menthol is known to have inhibitory actions on voltage-gated calcium $[97,161]$ and sodium channels [96] expressed in primary sensory neurons and both effects may also contribute to the inhibition of excitability of airway chemosensitive terminals. Interestingly, the same study found that menthol metabolites produced a mild form of irritation by activation of TRPA1 channels.

\section{TRPM8 AND COLD-INDUCED URTICARIA}

Cold-induced urticaria is a rare skin condition characterized by erythematous, pruritic weals following exposure to cold stimuli. Systemic shock and hypotension after immersion in cold water represent a potentially lifethreatening situation in these patients. There are acquired and familial forms of the disease and the pathogenesis is poorly understood. Activation of mast cells by an anti-IgE dependent mechanism is thought to play a role [162]. A recent study suggested the participation of TRPM8 in coldinduced urticaria [163]. The authors documented the expression of TRPM8 in RBL-2H3 cells, a rat basophilic leukemia mast cell line. Moreover, application of menthol or cold stimuli produced a dose-dependent release of histamine from these cells. In contrast, a study performed on humans found no evidence of TRPM8 expression in mast cells [164]. Also, these cells did not degranulate in response to cold or to application of TRPM8 agonists (menthol and WS-12). Finally, cutaneous anaphylactic responses and the activation of mast cells from TRPM8-/- mice were similar to WT, strongly suggesting that TRPM8 plays no role in the induction of cold-induced urticaria [164].

\section{TRPA1 AND COLD PAIN}

Although this review focuses on the role of TRPM8 in cold pain, we should briefly discuss the possible role of TRPA1 in cold nociception, a controversial issue in the literature [reviewed by 165]. As already indicated, TRPA1 was originally identified as a TRP channel activated by noxious cold [15]. Subsequent characterization of TRPA1 $\mathrm{KO}$ mice resulted in conflicting results as far as cold sensing deficits [16, 166, 167]. TRPA1 is now recognized as a critical chemosensor in nociceptor terminals [reviewed by 168], co-expressed with TRPV1, activated by bradykinin and important for the detection of many chemical irritants and oxidants $[167,169,170]$. Other studies suggest a role of 
TRPA1 in somatic and visceral mechanosensation [171173].

Recently, a TRPA1 gain of function mutation was identified in a Colombian family [174]. Affected individuals manifest an episodic pain syndrome triggered by physical stress, including fasting, fatigue and cold. Psychophysical quantitative sensory testing did not reveal alterations in cold pain thresholds. In contrast, the mutant channel, with a point mutation in the S4 transmembrane segment, showed greater activation by cold temperature, characterized by larger shift in the activation curve towards negative potentials compared to wildtype channels.

In our opinion, TRPA1 does not play a significant role in acute noxious cold sensation by somatic sensory neurons innervating the skin [175]. Most findings in the literature are consistent with this view. In healthy volunteers, application of cinnamaldehyde to the skin does not evoke cold sensations, rather it evokes burning pain and reduces the threshold for heat pain [116]. Moreover, cinnamaldehyde $(10 \%)$ does not affect cold pain thresholds in humans [114] and mustard oil, another TRPA1 agonist, does not sensitise spinal dorsal horn neurones to peripheral noxious cold stimulation [176]. In vivo, cold fibers are not modulated by TRPA1 agonists or antagonists (i.e. RR) [177]. Systemic treatment of adult mice with resiniferatoxin, an ultrapotent vanilloid agonists, destroyed TRPV1/TRPA1 expressing nociceptors. Surprisingly, these animals showed a significant hyperalgesia to cold [63]. Compared to the action of various chemical agonists, the activation of TRPA1 by cold temperature is very modest $[66,178]$. However, some human studies suggest a possible role of TRPA1 in cold sensation. For example, application of TRPA1 agonists to the tongue induces a brief cold hyperalgesia [179].

In contrast to most evidence against a role of TRPA1 in physiological noxious cold sensing, this channel is clearly involved in mediating cold hypersensitivity after inflammatory or neuropathic nerve injury [126, 180, 181]. In line with this view, intrathecal delivery of antisense oligodeoxynucleotides or TPRA1 antagonists has no effect on cold-evoked behaviours in normal animals but reduces the cold hypersensitivity seen after nerve injury [71] or inflammation [180,182]. Whether this activation is direct or involves intracellular mediators (e.g. calcium elevations) remains unclear $[16,183]$. Notably, many visceral neurons in the vagus nerve are cold-sensitive by a TRPA1-dependent mechanism [184]. Regardless of the role of TRPA1 in physiological cold transduction, TRPA1 modulators have promising potential in the treatment of pathological cold pain [185].

\section{CONCLUDING REMARKS}

A couple of years ago we compared the therapeutic prospects of TRPM8 channel modulators in the treatment of cold pain to the tip of a floating iceberg, showing some promise but with much of this potential still hidden beneath the surface [22]. Rather than melting, this promise appears to be gaining strength. Research published mostly in the last two years indicates that TRPM8 could be involved in the development of cold hyperalgesia in different diseases and syndromes. The diverse neurochemical phenotype of TRPM8-expressing neurons, the wide range of thermal thresholds and the behavioural results of TRPM8 KO mice do indeed suggest a role for TRPM8 in cold pain. Thus, TRPM8 could play dual actions, being analgesic or proalgesic depending on context, peripheral territory and degree of activation. Part of the problem, limiting the conclusive power of the published studies, resides in the fact that most conclusions regarding the role of TRPM8 in cold nociception are based on studies that used pharmacological tools that are no longer considered specific for TRPM8. For example, topical application of menthol to the skin evokes spontaneous sensations of pain in humans $[113,114]$ and activates cold-sensitive nociceptors [118]. However, it is clear now that menthol can also activate other nociceptorspecific channels, like TRPA1 [107], limiting the conclusive power of the aforesaid studies.

On the other hand, activation of cold-sensitive thermoreceptors could also alleviate some forms of pain, itch and airway irritation. Another interesting development is the realization that cold-sensitive and menthol-sensitive afferents play important roles in disorders that may not be categorized as strictly painful, such as eye discomfort and dry eye disease. In the future, these may represent novel therapeutic applications for TRPM8 modulators

Currently, one limitation from the experimental and the clinical point of view is the paucity of specific TRPM8 antagonists available, although things may change rapidly if one reviews the patent literature. Once more compounds enter clinical trials, the value of TRPM8 antagonists in different pain conditions will be clarified. Finally, the possible adverse effects of these compounds on thermoregulation should not be overlooked [35, 186, 187].

\section{CONFLICT OF INTEREST}

The authors confirm that this article content has no conflicts of interest.

\section{ACKNOWLEDGEMENTS}

The authors are grateful to former and current members of the Sensory Transduction and Nociception Group that contributed to the original research cited in this review. C. Fernández-Peña holds a predoctoral fellowship from the Generalitat Valenciana (GRISOLIA/2008/025). We also like to acknowledge funding from the Spanish MICINN projects SAF2010-14990 and PROMETEO 2010-046 to F. Viana and CONSOLIDER-INGENIO 2010 CSD2007-0002 to C. Belmonte.

\section{REFERENCES}

[1] Ochoa JL, Yarnitsky D. The triple cold syndrome. Cold hyperalgesia, cold hypoaesthesia and cold skin in peripheral nerve disease. Brain 1994; 117(Pt 1): 185-97.

[2] Wahren LK, Torebjork E. Quantitative sensory tests in patients with neuralgia 11 to 25 years after injury. Pain 1992; 48: 237-44.

[3] Bowsher D, Haggett C. Paradoxical burning sensation produced by cold stimulation in patients with neuropathic pain. Pain $2005 ; 117$ : 230.

[4] Carlsson IK, Rosen B, Dahlin LB. Self-reported cold sensitivity in normal subjects and in patients with traumatic hand injuries or hand-arm vibration syndrome. BMC Musculoskelet Disord 2010; 11: 89 .

[5] Kim SH, Chung JM. An experimental model for peripheral neuropathy produced by segmental spinal nerve ligation in the rat. Pain 1992; 50: 355-63. 
[6] Collins ED, Novak CB, Mackinnon SE, Weisenborn SA. Longterm follow-up evaluation of cold sensitivity following nerve injury. J Hand Surg Am 1996; 21: 1078-85.

[7] Kiernan MC. The pain with platinum: oxaliplatin and neuropathy. Eur J Cancer 2007; 43: 2631-3.

[8] Basbaum AI, Bautista DM, Scherrer G, Julius D. Cellular and molecular mechanisms of pain. Cell 2009; 139: 267-84.

[9] Belmonte C, Brock JA, Viana F. Converting cold into pain. Exp Brain Res 2009; 196: 13-30.

[10] Bandell M, Macpherson LJ, Patapoutian A. From chills to chilis: mechanisms for thermosensation and chemesthesis via thermoTRPs. Curr Opin Neurobiol 2007; 17: 490-7.

[11] Talavera K, Nilius B, Voets T. Neuronal TRP channels: thermometers, pathfinders and life-savers. Trends Neurosci 2008; 31: 287-95.

[12] Bautista DM, Siemens J, Glazer JM, et al. The menthol receptor TRPM8 is the principal detector of environmental cold. Nature 2007; 448: 204-8.

[13] Dhaka A, Murray AN, Mathur J, Earley TJ, Petrus MJ, Patapoutian A. TRPM8 is required for cold sensation in mice. Neuron 2007; 54: 371-8.

[14] Colburn RW, Lubin ML, Stone DJ, et al. Attenuated cold sensitivity in trpm8 null mice. Neuron 2007; 54: 379-86.

[15] Story GM, Peier AM, Reeve AJ, et al. ANKTM1, a TRP-like channel expressed in nociceptive neurons, is activated by cold temperatures. Cell 2003; 112: 819-29.

[16] Karashima Y, Talavera K, Everaerts W, et al. TRPA1 acts as a cold sensor in vitro and in vivo. Proc Natl Acad Sci USA 2009; 106: 1273-8.

[17] Foulkes T, Wood JN. Mechanisms of cold pain. Channels (Austin) 2007; 1: 154-60.

[18] McKemy DD, Neuhausser WM, Julius D. Identification of a cold receptor reveals a general role for TRP channels in thermosensation. Nature 2002; 416: 52-8.

[19] Peier AM, Moqrich A, Hergarden AC, et al. A TRP channel that senses cold stimuli and menthol. Cell 2002; 108: 705-15.

[20] Bodding M, Wissenbach U, Flockerzi V. Characterisation of TRPM8 as a pharmacophore receptor. Cell Calcium 2007; 42: 61828.

[21] Daniels RL, McKemy DD. Mice left out in the cold: commentary on the phenotype of TRPM8-nulls. Mol Pain 2007; 3: 23.

[22] Malkia A, Morenilla-Palao C, Viana F. the emerging pharmacology of trpm8 channels: hidden therapeutic potential underneath a cold surface. Curr Pharm Biotechnol 2011; 12(1): 54-67.

[23] Brauchi S, Orio P, Latorre R. Clues to understanding cold sensation: thermodynamics and electrophysiological analysis of the cold receptor TRPM8. Proc Natl Acad Sci USA 2004; 101: 15494-9.

[24] Latorre R, Brauchi S, Madrid R, Orio P. A cool channel in cold transduction. Physiology (Bethesda) 2011; 26: 273-85.

[25] Voets T, Owsianik G, Nilius B. TRPM8. Handb Exp Pharmacol 2007; 329-44.

[26] McCoy DD, Knowlton WM, McKemy DD. Scraping through the ice: uncovering the role of TRPM8 in cold transduction. Am J Physiol Regul Integr Comp Physiol 2011; 300: R1278-87.

[27] Wong GY, Gavva NR. Therapeutic potential of vanilloid receptor TRPV1 agonists and antagonists as analgesics: Recent advances and setbacks. Brain Res Rev 2009; 60: 267-77.

[28] Moran MM, McAlexander MA, Biro T, Szallasi A. Transient receptor potential channels as therapeutic targets. Nat Rev Drug Discov 2011; 10: 601-20.

[29] Madrid R, Donovan-Rodriguez T, Meseguer V, Acosta MC, Belmonte C, Viana F. Contribution of TRPM8 channels to cold transduction in primary sensory neurons and peripheral nerve terminals. J Neurosci 2006; 26: 12512-25.

[30] de la Pena E, Malkia A, Cabedo H, Belmonte C, Viana F. The contribution of TRPM8 channels to cold sensing in mammalian neurones. J Physiol 2005; 567: 415-26.

[31] Malkia A, Madrid R, Meseguer V, et al. Bidirectional shifts of TRPM8 channel gating by temperature and chemical agents modulate the cold sensitivity of mammalian thermoreceptors. J Physiol 2007; 581: 155-74.

[32] Reid G. ThermoTRP channels and cold sensing: what are they really up to? Pflugers Arch 2005; 451: 250-63.

[33] Voets T, Droogmans G, Wissenbach U, Janssens A, Flockerzi V, Nilius B. The principle of temperature-dependent gating in coldand heat-sensitive TRP channels. Nature 2004; 430: 748-54.
[34] Malkia A, Pertusa M, Fernandez-Ballester G, Ferrer-Montiel A, Viana F. Differential role of the menthol-binding residue Y745 in the antagonism of thermally gated TRPM8 channels. Mol Pain 2009; 5: 62 .

[35] Knowlton WM, Daniels RL, Palkar R, McCoy DD, McKemy DD. Pharmacological blockade of TRPM8 ion channels alters cold and cold pain responses in mice. PLoS ONE 2011; 6: e25894.

[36] Rohacs T, Lopes CM, Michailidis I, Logothetis DE. PI $(4,5) \mathrm{P} 2$ regulates the activation and desensitization of TRPM8 channels through the TRP domain. Nat Neurosci 2005; 8: 626-34.

[37] Daniels RL, Takashima Y, McKemy DD Activity of the neuronal cold sensor TRPM8 is regulated by phospholipase $\mathrm{C}$ via the phospholipid phosphoinositol 4,5-bisphosphate. J Biol Chem 2009; 284: 1570-82.

[38] Abe J, Hosokawa H, Sawada Y, Matsumura K, Kobayashi S. $\mathrm{Ca} 2+$-dependent PKC activation mediates menthol-induced desensitization of transient receptor potential M8. Neurosci Lett 2006; 397: 140-4.

[39] Premkumar LS, Raisinghani M, Pingle SC, Long C, Pimentel F. Downregulation of transient receptor potential melastatin 8 by protein kinase C-mediated dephosphorylation. J Neurosci 2005; 25: 11322-9.

[40] Vanden Abeele F, Zholos A, Bidaux G, et al. iPLA2-dependent gating of TRPM8 by lysophospholipids. J Biol Chem 2006; 281(52): 40174-82.

[41] Linte RM, Ciobanu C, Reid G, Babes A. Desensitization of coldand menthol-sensitive rat dorsal root ganglion neurones by inflammatory mediators. Exp Brain Res 2007; 178: 89-98.

[42] Zakharian E, Thyagarajan B, French RJ, Pavlov E, Rohacs T. Inorganic polyphosphate modulates TRPM8 channels. PLoS ONE 2009; 4: e5404.

[43] Morenilla-Palao C, Pertusa M, Meseguer V, Cabedo H, Viana F. Lipid Raft Segregation Modulates TRPM8 Channel Activity. J Biol Chem 2009; 284(49): 9215-24.

[44] Veliz LA, Toro CA, Vivar JP, et al. Near-membrane dynamics and capture of TRPM8 channels within transient confinement domains. PLoS ONE 2010; 5: e13290.

[45] Dragoni I, Guida E, McIntyre P. The cold and menthol receptor TRPM8 contains a functionally important double cysteine motif. J Biol Chem 2006; 281(49): 37353-60.

[46] Erler I, Al Ansary DM, Wissenbach U, Wagner TF, Flockerzi V, Niemeyer BA. Trafficking and assembly of the cold-sensitive TRPM8 channel. J Biol Chem 2006; 281: 38396-404.

[47] Pertusa M, Madrid R, Morenilla-Palao C, Belmonte C, Viana F. The N-glycosylation of TRPM8 channels modulates the temperature sensitivity of cold-thermoreceptor neurons. J Biol Chem 2012; 287(22): 18218-29.

[48] Andersson DA, Nash M, Bevan S. Modulation of the cold-activated channel TRPM8 by lysophospholipids and polyunsaturated fatty acids. J Neurosci 2007; 27: 3347-55.

[49] Bidaux G, Beck B, Zholos A, et al. Regulation of activity of transient receptor potential melastatin 8 (TRPM8) channel by its short isoforms. J Biol Chem 2012; 287: 2948-62.

[50] Takashima Y, Daniels RL, Knowlton W, Teng J, Liman ER, McKemy DD. Diversity in the neural circuitry of cold sensing revealed by genetic axonal labeling of transient receptor potential melastatin 8 neurons. J Neurosci 2007; 27: 14147-57.

[51] Dhaka A, Earley TJ, Watson J, Patapoutian A. Visualizing cold spots: TRPM8-expressing sensory neurons and their projections. J Neurosci 2008; 28: 566-75.

[52] Parra A, Madrid R, Echevarria D, et al. Ocular surface wetness is regulated by TRPM8-dependent cold thermoreceptors of the cornea. Nat Med 2010; 16: 1396-9.

[53] Abe J, Hosokawa H, Okazawa M, et al. TRPM8 protein localization in trigeminal ganglion and taste papillae. Brain Res Mol Brain Res 2005; 136: 91-8.

[54] Harrington AM, Hughes PA, Martin CM, et al. A novel role for TRPM8 in visceral afferent function. Pain 2011; 152: 1459-68.

[55] Axelsson HE, Minde JK, Sonesson A, Toolanen G, Hogestatt ED, Zygmunt PM. Transient receptor potential vanilloid 1, vanilloid 2 and melastatin 8 immunoreactive nerve fibers in human skin from individuals with and without Norrbottnian congenital insensitivity to pain. Neuroscience 2009; 162: 1322-32.

[56] Hensel H, Zotterman Y. The response of the cold receptors to constant cooling. Acta Physiol Scan 1951; 22: 96-113. 
[57] Schafer K, Braun HA, Isenberg C. Effect of menthol on cold receptor activity. Analysis of receptor processes. J Gen Physiol 1986; 88: 757-76.

[58] Viana F, de la Pena E, Belmonte C. Specificity of cold thermotransduction is determined by differential ionic channel expression. Nat Neurosci 2002; 5: 254-60.

[59] Babes A, Zorzon D, Reid G. Two populations of cold-sensitive neurons in rat dorsal root ganglia and their modulation by nerve growth factor. Eur J Neurosci 2004; 20: 2276-82.

[60] Okazawa M, Inoue W, Hori A, Hosokawa H, Matsumura K, Kobayashi S. Noxious heat receptors present in cold-sensory cells in rats. Neurosci Lett 2004; 359: 33-6.

[61] Xing H, Ling J, Chen M, Gu JG. Chemical and cold sensitivity of two distinct populations of trpm8-expressing somatosensory neurons. J Neurophysiol 2006; 95: 1221-30.

[62] Frederick J, Buck ME, Matson DJ, Cortright DN. Increased TRPA1, TRPM8, and TRPV2 expression in dorsal root ganglia by nerve injury. Biochem Biophys Res Commun 2007; 358: 1058-64.

[63] Pecze L, Pelsoczi P, Kecskes M, et al. Resiniferatoxin mediated ablation of TRPV1+ neurons removes TRPA1 as well. Can J Neurol Sci 2009; 36: 234-41.

[64] Reid G, Flonta ML. Physiology. Cold current in thermoreceptive neurons. Nature 2001; 413: 480 .

[65] Okazawa M, Takao K, Hori A, Shiraki T, Matsumura K, Kobayashi $\mathrm{S}$. Ionic basis of cold receptors acting as thermostats. J Neurosci 2002; 22: 3994-4001.

[66] Madrid R, de la PE, Donovan-Rodriguez T, Belmonte C, Viana F. Variable threshold of trigeminal cold-thermosensitive neurons is determined by a balance between TRPM8 and Kv1 potassium channels. J Neurosci 2009; 29: 3120-31.

[67] Mizushima T, Obata K, Katsura H, et al. Noxious cold stimulation induces mitogen-activated protein kinase activation in transient receptor potential (TRP) channels T. Neuroscience 2006; 140: 133748.

[68] Mizushima T, Obata K, Yamanaka H, et al. Activation of p38 MAPK in primary afferent neurons by noxious stimulation and its involvement in the development of thermal hyperalgesia. Pain 2005; 113: 51-60.

[69] Obata K, Katsura H, Mizushima T, et al. TRPA1 induced in sensory neurons contributes to cold hyperalgesia after inflammation and nerve injury. J Clin Invest 2005; 115(9): 2393-401.

[70] Ji G, Zhou S, Carlton SM. Intact Adelta-fibers up-regulate transient receptor potential $\mathrm{A} 1$ and contribute to cold hypersensitivity in neuropathic rats. Neuroscience 2008; 154: 1054-66.

[71] Katsura H, Obata K, Mizushima T, et al. Antisense knock down of TRPA1, but not TRPM8, alleviates cold hyperalgesia after spinal nerve ligation in rats. Exp Neurol 2006; 200(1): 112-23.

[72] Persson AK, Xu XJ, Wiesenfeld-Hallin Z, Devor M, Fried K. Expression of DRG candidate pain molecules after nerve injury--a comparative study among five inbred mouse strains with contrasting pain phenotypes. J Peripher Nerv Syst 2010; 15: 26-39.

[73] Ji G, Zhou S, Kochukov MY, Westlund KN, Carlton SM. Plasticity in intact A delta- and C-fibers contributes to cold hypersensitivity in neuropathic rats. Neuroscience 2007; 150: 182-93.

[74] Djouhri L, Wrigley D, Thut PD, Gold MS. Spinal nerve injury increases the percentage of cold-responsive DRG neurons. Neuroreport 2004; 15: 457-60.

[75] Xing H, Chen M, Ling J, Tan W, Gu JG. TRPM8 mechanism of cold allodynia after chronic nerve injury. J Neurosci 2007; 27 : 13680-90.

[76] Caspani O, Zurborg S, Labuz D, Heppenstall PA. The contribution of TRPM8 and TRPA1 channels to cold allodynia and neuropathic pain. PLoS ONE 2009; 4: e7383.

[77] Huang HL, Cendan CM, Roza C, et al. Proteomic profiling of neuromas reveals alterations in protein composition and local protein synthesis in hyper-excitable nerves. Mol Pain 2008; 4: 33.

[78] Brosseau L, Yonge KA, Robinson V, et al. Thermotherapy for treatment of osteoarthritis. Cochrane Database Syst Rev 2003; CD004522.

[79] Nadler SF, Weingand K, Kruse RJ. The physiologic basis and clinical applications of cryotherapy and thermotherapy for the pain practitioner. Pain Physician 2004; 7 : 395-9.

[80] Airaksinen OV, Kyrklund N, Latvala K, Kouri JP, Gronblad M, Kolari P. Efficacy of cold gel for soft tissue injuries: a prospective randomized double-blinded trial. Am J Sports Med 2003; 31: 6804.
[81] Algafly AA, George KP. The effect of cryotherapy on nerve conduction velocity, pain threshold and pain tolerance. Br J Sports Med 2007; 41: 365-9.

[82] LaMotte RH, Lundberg LE, Torebjork HE. Pain, hyperalgesia and activity in nociceptive $\mathrm{C}$ units in humans after intradermal injection of capsaicin. J Physiol 1992; 448: 749-64

[83] Caterina MJ, Schumacher MA, Tominaga M, Rosen TA, Levine JD, Julius D. The capsaicin receptor: a heat-activated ion channel in the pain pathway. Nature 1997; 389: 816-24.

[84] Yarnitsky D, Ochoa JL. Release of cold-induced burning pain by block of cold-specific afferent input. Brain 1990; 113(Pt 4): 893902.

[85] Wahren LK, Torebjork E, Jorum E. Central suppression of coldinduced C fibre pain by myelinated fibre input. Pain 1989; 38: 313 9.

[86] Eccles R. Menthol and related cooling compounds. J Pharm Pharmacol 1994; 46: 618-30.

[87] Patel T, Ishiuji Y, Yosipovitch G. Menthol: a refreshing look at this ancient compound. J Am Acad Dermatol 2007; 57: 873-8.

[88] Davies SJ, Harding LM, Baranowski AP. A novel treatment of postherpetic neuralgia using peppermint oil. Clin J Pain 2002; 18 : 200-2.

[89] Green BG. Menthol inhibits the perception of warmth. Physiol Behav 1986; 38: 833-8.

[90] Green BG, McAuliffe BL. Menthol desensitization of capsaicin irritation. Evidence of a short- term anti-nociceptive effect. Physiol Behav 2000; 68: 631-9.

[91] Bromm B, Scharein E, Darsow U, Ring J. Effects of menthol and cold on histamine-induced itch and skin reactions in man. Neurosci Lett 1995; 187: 157-60.

[92] Yosipovitch G, Szolar C, Hui XY, Maibach H. Effect of topically applied menthol on thermal, pain and itch sensations and biophysical properties of the skin. Arch Dermatol 1996; Res 288: 245-8.

[93] Klein AH, Sawyer CM, Carstens MI, Tsagareli MG, Tsiklauri N, Carstens E. Topical application of L-menthol induces heat analgesia, mechanical allodynia, and a biphasic effect on cold sensitivity in rats. Behav Brain Res 2010; 212: 179-86.

[94] Proudfoot CJ, Garry EM, Cottrell DF, et al. Analgesia Mediated by the TRPM8 Cold Receptor in Chronic Neuropathic Pain. Curr Biol 2006; 16: 1591-1605.

[95] Haeseler G, Maue D, Grosskreutz J, et al. Voltage-dependent block of neuronal and skeletal muscle sodium channels by thymol and menthol. Eur J Anaesthesiol 2002; 19: 571-9.

[96] Gaudioso C, Hao J, Martin-Eauclaire MF, Gabriac M, Delmas P. Menthol pain relief through cumulative inactivation of voltagegated sodium channels. Pain 2012; 153: 473-84.

[97] Swandulla D, Carbone E, Schafer K, Lux HD. Effect of menthol on two types of $\mathrm{Ca}$ currents in cultured sensory neurons of vertebrates. Pflugers Arch 1987; 409: 52-9.

[98] Hall AC, Turcotte CM, Betts BA, Yeung WY, Agyeman AS, Burk LA. Modulation of human GABAA and glycine receptor currents by menthol and related monoterpenoids. Eur J Pharmacol 2004; 506: 9-16.

[99] Zhang XB, Jiang $\mathrm{P}$, Gong $\mathrm{N}$, et al. A-type GABA receptor as a central target of TRPM8 agonist menthol. PLoS ONE 2008; 3: e3386.

[100] Tani M, Onimaru H, Ikeda K, Kawakami K, Homma I. Menthol inhibits the respiratory rhythm in brainstem preparations of the newborn rats. Neuroreport 2010; 21: 1095-9.

[101] van Zanten SV. Review: fibre, antispasmodics, and peppermint oil are all effective for irritable bowel syndrome. Evid Based Med 2009; 14: 84

[102] Harrison JL, Davis KD. Cold-evoked pain varies with skin type and cooling rate: a psychophysical study in humans. Pain 1999; 83: 123-35.

[103] Cox JJ, Reimann F, Nicholas AK, et al. An SCN9A channelopathy causes congenital inability to experience pain. Nature 2006; 444 : 894-8.

[104] Hatem S, Attal N, Willer JC, Bouhassira D. Psychophysical study of the effects of topical application of menthol in healthy volunteers. Pain 2006; 122: 190-6.

[105] Zimmermann K, Lennerz JK, Hein A, et al. Transient receptor potential cation channel, subfamily C, member 5 (TRPC5) is a cold-transducer in the peripheral nervous system. Proc Natl Acad Sci USA 2011; 108: 18114-9. 
[106] Green BG, Pope JV. Innocuous cooling can produce nociceptive sensations that are inhibited during dynamic mechanical contact. Exp Brain Res 2003; 148: 290-9.

[107] Karashima Y, Damann N, Prenen J, Talavera K, Segal A, Voets T, Nilius B Bimodal action of menthol on the transient receptor potential channel TRPA1. J Neurosci 2007; 27: 9874-9884.

[108] Xiao B, Dubin AE, Bursulaya B, Viswanath V, Jegla TJ, Patapoutian A. Identification of transmembrane domain 5 as a critical molecular determinant of menthol sensitivity in mammalian TRPA1 channels. J Neurosci 2008; 28: 9640-51.

[109] Macpherson LJ, Hwang SW, Miyamoto T, Dubin AE, Patapoutian A, Story GM. More than cool: Promiscuous relationships of menthol and other sensory compounds. Mol Cell Neurosci 2006; 32(4): 335-43.

[110] Gentry C, Stoakley N, Andersson DA, Bevan S. The roles of iPLA2, TRPM8 and TRPA1 in chemically induced cold hypersensitivity. Mol Pain 2010; 6: 4.

[111] Green BG. The sensory effects of 1-menthol on human skin. Somatosens Mot Res 1992; 9: 235-44.

[112] Hensel H. Thermoreception and temperature regulation. Monogr Physiol Soc 1981; 38: 1-321.

[113] Wasner G, Schattschneider J, Binder A, Baron R. Topical menthol-a human model for cold pain by activation and sensitization of $\mathrm{C}$ nociceptors. Brain 2004; 127: 1159-71.

[114] Namer B, Seifert F, Handwerker HO, Maihofner C. TRPA1 and TRPM8 activation in humans: effects of cinnamaldehyde and menthol. Neuroreport 2005; 16: 955-9.

[115] Green BG, Schoen KL. Thermal and nociceptive sensations from menthol and their suppression by dynamic contact. Behav Brain Res 2007; 176: 284-91.

[116] Roberts K, Shenoy R, Anand P. A novel human volunteer pain model using contact heat evoked potentials (CHEP) following topical skin application of transient receptor potential agonists capsaicin, menthol and cinnamaldehyde. J Clin Neurosci 2011; 18: 926-32.

[117] Binder A, Stengel M, Klebe O, Wasner G, Baron R. Topical highconcentration $(40 \%)$ menthol-somatosensory profile of a human surrogate pain model. J Pain 2011; 12: 764-73.

[118] Serra J, Sola R, Quiles C, et al. C-nociceptors sensitized to cold in a patient with small-fiber neuropathy and cold allodynia. Pain 2009; 147: 46-53.

[119] Wasner G, Naleschinski D, Binder A, Schattschneider J, McLachlan EM, Baron R. The effect of menthol on cold allodynia in patients with neuropathic pain. Pain Med 2008; 9: 354-8.

[120] Su L, Wang C, Yu YH, Ren YY, Xie KL, Wang GL. Role of TRPM8 in dorsal root ganglion in nerve injury-induced chronic pain. BMC Neurosci 2011; 12: 120.

[121] Lehky TJ, Leonard GD, Wilson RH, Grem JL, Floeter MK. Oxaliplatin-induced neurotoxicity: acute hyperexcitability and chronic neuropathy. Muscle Nerve 2004; 29: 387-92.

[122] Bennett BK, Park SB, Lin CS, Friedlander ML, Kiernan MC, Goldstein D. Impact of oxaliplatin-induced neuropathy: a patient perspective. Support Care Cancer 2012; 20(11): 2959-67.

[123] Gauchan P, Andoh T, Kato A, Kuraishi Y. Involvement of increased expression of transient receptor potential melastatin 8 in oxaliplatin-induced cold allodynia in mice. Neurosci Lett 2009; 458: 93-5.

[124] Descoeur J, Pereira V, Pizzoccaro A,et al. Oxaliplatin-induced cold hypersensitivity is due to remodelling of ion channel expression in nociceptors. EMBO Mol Med 2011; 3: 266-78.

[125] Orio P, Madrid R, de la PE, et al. Characteristics and physiological role of hyperpolarization activated currents in mouse cold thermoreceptors. J Physiol 2009; 587: 1961-76.

[126] Nassini R, Gees M, Harrison S, et al. Oxaliplatin elicits mechanical and cold allodynia in rodents via TRPA1 receptor stimulation. Pain 2011; 152(7): 1621-3.

[127] Sittl R, Lampert A, Huth T, et al. Anticancer drug oxaliplatin induces acute cooling-aggravated neuropathy via sodium channel subtype NaV1.6-resurgent and persistent current. Proc Natl Acad Sci USA 2012; 109(17): 6704-9.

[128] Sessle BJ. Peripheral and central mechanisms of orofacial inflammatory pain. Int Rev Neurobiol 2011; 97: 179-206.

[129] Benoliel R, Eliav E. Neuropathic orofacial pain. Oral Maxillofac Surg Clin North Am 2008; 20: 237-54, vii.
[130] Eide PK, Rabben T. Trigeminal neuropathic pain: pathophysiological mechanisms examined by quantitative assessment of abnormal pain and sensory perception. Neurosurgery 1998; 43: 1103-10.

[131] Chichorro JG, Zampronio AR, Souza GE, Rae GA. Orofacial cold hyperalgesia due to infraorbital nerve constriction injury in rats: reversal by endothelin receptor antagonists but not non-steroidal antiinflammatory drugs. Pain 2006; 123: 64-74.

[132] Nealen ML, Gold MS, Thut PD, Caterina MJ. TRPM8 mRNA is expressed in a subset of cold-responsive trigeminal neurons from rat. J Neurophysiol 2003; 90: 515-20.

[133] Magloire H, Maurin JC, Couble ML, et al. Topical review. Dental pain and odontoblasts: facts and hypotheses. J Orofac Pain 2010; 24: 335-49.

[134] Markowitz K, Pashley DH. Discovering new treatments for sensitive teeth: the long path from biology to therapy. J Oral Rehabil 2008; 35: 300-15.

[135] Park CK, Kim MS, Fang Z, et al. Functional expression of thermotransient receptor potential channels in dental primary afferent neurons: implication for tooth pain. J Biol Chem 2006; 281: 17304-11.

[136] Zimmermann K, Leffler A, Babes A, et al. Sensory neuron sodium channel Nav1.8 is essential for pain at low temperatures. Nature 2007; 447: 856-9.

[137] El Karim IA, Linden GJ, Curtis TM, et al. Human odontoblasts express functional thermo-sensitive TRP channels: implications for dentin sensitivity. Pain 2011; 152: 2211-23.

[138] Son AR, Yang YM, Hong JH, Lee SI, Shibukawa Y, Shin DM. Odontoblast TRP channels and thermo/mechanical transmission. J Dent Res 2009; 88: 1014-9.

[139] Yeon KY, Chung G, Shin MS, Jung SJ, Kim JS, Oh SB. Adult rat odontoblasts lack noxious thermal sensitivity. J Dent Res 2009; 88: 328-32.

[140] Alvarado LT, Perry GM, Hargreaves KM, Henry MA. TRPM8 Axonal expression is decreased in painful human teeth with irreversible pulpitis and cold hyperalgesia. J Endod 2007; 33: 1167-71.

[141] Haas ET, Rowland K, Gautam M. Tooth injury increases expression of the cold sensitive TRP channel TRPA1 in trigeminal neurons. Arch Oral Biol 2011; 56: 1604-9.

[142] Chasman DI, Schurks M, Anttila V, et al. Genome-wide association study reveals three susceptibility loci for common migraine in the general population. Nat Genet 2011; 43: 695-8.

[143] Nassini R, Materazzi S, Vriens J, et al. The 'headache tree' via umbellulone and TRPA1 activates the trigeminovascular system. Brain 2012; 135: 376-90.

[144] Kunkler PE, Ballard CJ, Oxford GS, Hurley JH. TRPA1 receptors mediate environmental irritant-induced meningeal vasodilatation. Pain 2011; 152(1): 38-44.

[145] Brock JA, McLachlan EM, Belmonte C. Tetrodotoxin-resistant impulses in single nociceptor nerve terminals in guinea-pig cornea. J Physiol 1998; 512(Pt 1): 211-7.

[146] Hirata H, Meng ID. Cold-sensitive corneal afferents respond to a variety of ocular stimuli central to tear production: implications for dry eye disease. Invest Ophthalmol Vis Sci 2010; 51: 3969-76.

[147] Acosta MC, Belmonte C, Gallar J. Sensory experiences in humans and single-unit activity in cats evoked by polymodal stimulation of the cornea. J Physiol 2001; 534: 511-25.

[148] Pflugfelder SC. Prevalence, burden, and pharmacoeconomics of dry eye disease. Am J Manag Care 2008; 14: S102-6.

[149] Lemp MA. Advances in understanding and managing dry eye disease. Am J Ophthalmol 2008; 146: 350-6.

[150] Dartt DA. Neural regulation of lacrimal gland secretory processes: relevance in dry eye diseases. Prog Retin Eye Res 2009; 28: 15577.

[151] Hirata H, Oshinsky ML. Ocular dryness excites two classes of corneal afferent neurons implicated in basal tearing in rats: involvement of transient receptor potential channels. J Neurophysiol 2012; 107: 1199-209.

[152] Belmonte C, Gallar J. Cold thermoreceptors, unexpected players in tear production and ocular dryness sensations. Invest Ophthalmol Vis Sci 2011; 52: 3888-92.

[153] Sant'Ambrogio G, Mathew OP, Sant'Ambrogio FB. Characteristics of laryngeal cold receptors. Respir Physiol 1988; 71: 287-97.

[154] Sant'Ambrogio FB, Anderson JW, Sant'Ambrogio G. Effect of 1menthol on laryngeal receptors. J Appl Physiol 1991; 70: 788-93.

[155] Zhou Y, Sun B, Li Q, Luo P, Dong L, Rong W. Sensitivity of bronchopulmonary receptors to cold and heat mediated by transient receptor potential cation channel subtypes in an ex vivo rat lung 
ceptor potential cation channel subtypes in an ex vivo rat lung preparation. Respir Physiol Neurobiol 2011; 177: 327-32.

[156] Li M, Li Q, Yang G, Kolosov VP, Perelman JM, Zhou XD. Cold temperature induces mucin hypersecretion from normal human bronchial epithelial cells in vitro through a transient receptor potential melastatin 8 (TRPM8)-mediated mechanism. J Allergy Clin Immunol 2011; 128: 626-34.

[157] Sabnis AS, Shadid M, Yost GS, Reilly CA. Human lung epithelial cells express a functional cold-sensing TRPM8 variant. Am J Respir Cell Mol Biol 2008; 39: 466-74.

[158] Klausner K. Menthol cigarettes and smoking initiation: a tobacco industry perspective. Tob Control 2011; 20(Suppl 2): ii12-ii19.

[159] Willis DN, Liu B, Ha MA, Jordt SE, Morris JB. Menthol attenuates respiratory irritation responses to multiple cigarette smoke irritants. FASEB J 2011; 25: 4434-44.

[160] Lashinger ES, Steiginga MS, Hieble JP, et al. AMTB, a TRPM8 channel blocker: evidence in rats for activity in overactive bladder and painful bladder syndrome. Am J Physiol Renal Physiol 2008; 295: F803-10.

[161] Swandulla D, Schafer K, Lux HD. Calcium channel current inactivation is selectively modulated by menthol. Neurosci Lett 1986; 68: 23-8.

[162] Wanderer AA, Hoffman HM. The spectrum of acquired and familial cold-induced urticaria/urticaria-like syndromes. Immunol Allergy Clin North Am 2004; 24: 259-86, vii.

[163] Cho Y, Jang Y, Yang YD, Lee CH, Lee Y, Oh U. TRPM8 mediates cold and menthol allergies associated with mast cell activation. Cell Calcium 2010; 48: 202-8.

[164] Medic N, Desai A, Komarow H, et al. Examination of the role of TRPM8 in human mast cell activation and its relevance to the etiology of cold-induced urticaria. Cell Calcium 2011; 50: 473-80.

[165] Kwan KY, Corey DP. Burning cold: involvement of TRPA1 in noxious cold sensation. J Gen Physiol 2009; 133: 251-6.

[166] Kwan KY, Allchorne AJ, Vollrath MA, et al. TRPA1 Contributes to Cold, Mechanical, and Chemical Nociception but Is Not Essential for Hair-Cell Transduction. Neuron 2006; 50: 277-89.

[167] Bautista DM, Jordt SE, Nikai T, et al. TRPA1 Mediates the Inflammatory Actions of Environmental Irritants and Proalgesic Agents. Cell 2006; 124: 1269-82.

[168] Viana F. Chemosensory properties of the trigeminal system. ACS Chem Neurosci 2011; 2: 38-50.

[169] Jordt SE, Bautista DM, Chuang HH, et al. Mustard oils and cannabinoids excite sensory nerve fibres through the TRP channel ANKTM1. Nature 2004; 427: 260-5.

[170] Macpherson LJ, Dubin AE, Evans MJ, et al. Noxious compounds activate TRPA1 ion channels through covalent modification of cysteines. Nature 2007; 445: 541-5.

[171] Brierley SM, Hughes PA, Page AJ, et al. The ion channel TRPA1 is required for normal mechanosensation and is modulated by algesic stimuli. Gastroenterology 2009; 137: 2084-95.
[172] Kwan KY, Glazer JM, Corey DP, Rice FL, Stucky CL. TRPA1 modulates mechanotransduction in cutaneous sensory neurons. J Neurosci 2009; 29: 4808-19.

[173] Yu S, Ouyang A. TRPA1 in bradykinin-induced mechanical hypersensitivity of vagal C fibers in guinea pig esophagus. Am J Physiol Gastrointest Liver Physiol 2009; 296: G255-65.

[174] Kremeyer B, Lopera F, Cox JJ, et al. A gain-of-function mutation in TRPA1 causes familial episodic pain syndrome. Neuron 2010; 66: 671-80.

[175] Knowlton WM, Bifolck-Fisher A, Bautista DM, McKemy DD. TRPM8, but not TRPA1, is required for neural and behavioral responses to acute noxious cold temperatures and cold-mimetics in vivo. Pain 2010; 150: 340-50.

[176] Sawyer CM, Carstens MI, Carstens E. Mustard oil enhances spinal neuronal responses to noxious heat but not cooling. Neurosci Lett 2009; 461: 271-4.

[177] Dunham JP, Leith JL, Lumb BM, Donaldson LF. Transient receptor potential channel A1 and noxious cold responses in rat cutaneous nociceptors. Neuroscience 2010; 165: 1412-19.

[178] del Camino D, Murphy S, Heiry M, et al. TRPA1 contributes to cold hypersensitivity. J Neurosci 2010; 30: 15165-74.

[179] Albin KC, Carstens MI, Carstens E. Modulation of Oral Heat and Cold Pain by Irritant Chemicals. Chem Senses 2008; 33(1): 3-15.

[180] da Costa DS, Meotti FC, Andrade EL, Leal PC, Motta EM, Calixto JB. The involvement of the transient receptor potential A1 (TRPA1) in the maintenance of mechanical and cold hyperalgesia in persistent inflammation. Pain 2010; 148: 431-7.

[181] Chen J, Joshi SK, DiDomenico S, et al. Selective blockade of TRPA1 channel attenuates pathological pain without altering noxious cold sensation or body temperature regulation. Pain 2011; 152: 1165-72.

[182] Petrus M, Peier AM, Bandell M, et al. A role of TRPA1 in mechanical hyperalgesia is revealed by pharmacological inhibition. Mol Pain 2007; 3: 40.

[183] Zurborg S, Yurgionas B, Jira JA, Caspani O, Heppenstall PA. Direct activation of the ion channel TRPA1 by $\mathrm{Ca}(2+)$. Nat Neurosci 2007 ; 10: 277-9.

[184] Fajardo O, Meseguer V, Belmonte C, Viana F. TRPA1 channels mediate cold temperature sensing in mammalian vagal sensory neurons: pharmacological and genetic evidence. J Neurosci 2008; 28: 7863-75.

[185] Viana F, Ferrer-Montiel A. TRPA1 modulators in preclinical development. Expert Opin Ther Pat 2009; 19: 1787-99.

[186] Almeida MC, Hew-Butler T, Soriano RN, et al. Pharmacological blockade of the cold receptor TRPM8 attenuates autonomic and behavioral cold defenses and decreases deep body temperature. J Neurosci 2012; 32: 2086-99.

[187] Tajino K, Hosokawa H, Maegawa S, Matsumura K, Dhaka A, Kobayashi S. Cooling-sensitive TRPM8 is thermostat of skin temperature against cooling. PLoS ONE 2011; 6: e17504.

Received: August 09, 2012

Revised: August 09, 2012

Accepted: August 16, 2012

(C) Fernández-Peña and Viana; Licensee Bentham Open.

This is an open access article licensed under the terms of the Creative Commons Attribution Non-Commercial License (http://creativecommons.org/licenses/by-nc/3.0/) which permits unrestricted, non-commercial use, distribution and reproduction in any medium, provided the work is properly cited. 